\title{
Postductal Coarctation of Aorta Causing Myocardial Ischaemia and Heart Failure in First Week of Life
}

\author{
K. A. HALLIDIE-SMITH \\ From the Department of Medicine (Clinical Cardiology), Royal Postgraduate Medical School, London
}

\begin{abstract}
Hallidie-Smith, K. A. (1972). Archives of Disease in Childhood, 47, 719. Postductal coarctation of aorta causing myocardial ischaemia and heart failure in first week of life. Two infants with isolated postductal coarctation of the aorta who developed heart failure in the first week of life are reported.

Possible factors contributing to symptomatology from this anomaly in the newborn period are discussed.

In these two infants there was some evidence that left ventricular myocardial necrosis was an important factor.
\end{abstract}

The natural history of coarctation of the aorta is incompletely known. While the defect is usually detected on routine physical examination of an asymptomatic child, nevertheless it is one of the most common causes of heart failure and death in early infancy (Keith, Rowe, and Vlad, 1967; Rowe and Mehrizi, 1968). Clearly the early development of heart failure may be often attributable to associated cardiac anomalies, and heart failure resulting from preductal coarctation is common in the first 6 weeks of life (Keith et al., 1967; Gasul, Arcilla, and Lev, 1966). However, heart failure in infancy may also result from postductal coarctation and a small number of symptomatic infants have been reported in whom this was the sole lesion (Tawes et al., 1969a; Sinha et al., 1969; Gasul et al., 1966; Bahn, Edwards, and DuShane, 1951; Kirklin et al., 1952; Glass, Mustard, and Keith, 1960; Lang and Nadas, 1956).

Over the past 2 years four infants with postductal coarctation of the aorta have been admitted to Hammersmith Hospital in cardiac failure which occurred under 2 weeks of age. Two of these patients had isolated postductal coarctation of the aorta and all four had successful surgical resection of the coarctation. It is proposed to describe these two babies and to discuss the possible factors contributing to the development of their heart failure in early infancy.

\section{Case Reports}

Case 1. A normal term delivery, birthweight $3 \mathrm{~kg}$. She was the third child of healthy Indian parents and

Received 22 February 1972. was well until the 7th day of life when she collapsed and was found to be in heart failure with absent femoral pulses. She was treated with digitalis and diuretics, and transferred on her 14th day with a diagnosis of coarctation of the aorta. On admission she was tachypnoeic and sweating, with hepatomegaly of $3 \mathrm{~cm}$ and splenomegaly of $1 \mathrm{~cm}$ below the costal margin; the jugular venous pressure was raised $4 \mathrm{~cm}$ above the sternal angle, and there was a cyanotic tinge to the mucous membranes. The brachial pulses were abnormally easily palpable and the femoral and foot pulses impalpable. The blood pressure in both arms was $125 / 75 \mathrm{mmHg}$ and the pressure in the legs was unrecordable by oscillometer. The pulmonary component of the second heart sound was accentuated, and third and fourth heart sounds were heard at the apex. There was a soft ejection systolic murmur at the left sternal edge. The ECG (Fig. 1a) showed a frontal plane axis of +110 and probable biventricular enlargement (tall $R$ and deep $S, V_{4}$ ). There were ST changes suggestive of anterolateral infarction with $\mathrm{qS}$ pattern in leads $I$ and aVL. A chest $x$-ray showed marked cardiomegaly and congested lung fields, suggestive of pulmonary oedema.

A clinical diagnosis of coarctation of the aorta was made and the possibility of an associated anomalous left coronary artery arising from the pulmonary artery was raised on the basis of the ECG. As the infant failed to improve on intensive medical treatment she was investigated 3 days later with a view to surgical treatment.

Right and left heart catheterization (Table) was carried out without premedication. A resting mean left atrial pressure of $25 \mathrm{~mm}$ was recorded, the left atrium being entered via a patent foramen ovale. The pressure in the ascending aorta was raised to $130 / 100 \mathrm{mmHg}$ (mean $120 \mathrm{~mm}$ ), pulmonary artery pressure to $75 / 40$ $\mathrm{mmHg}$, and right ventricular end-diastolic pressure to 
(a)

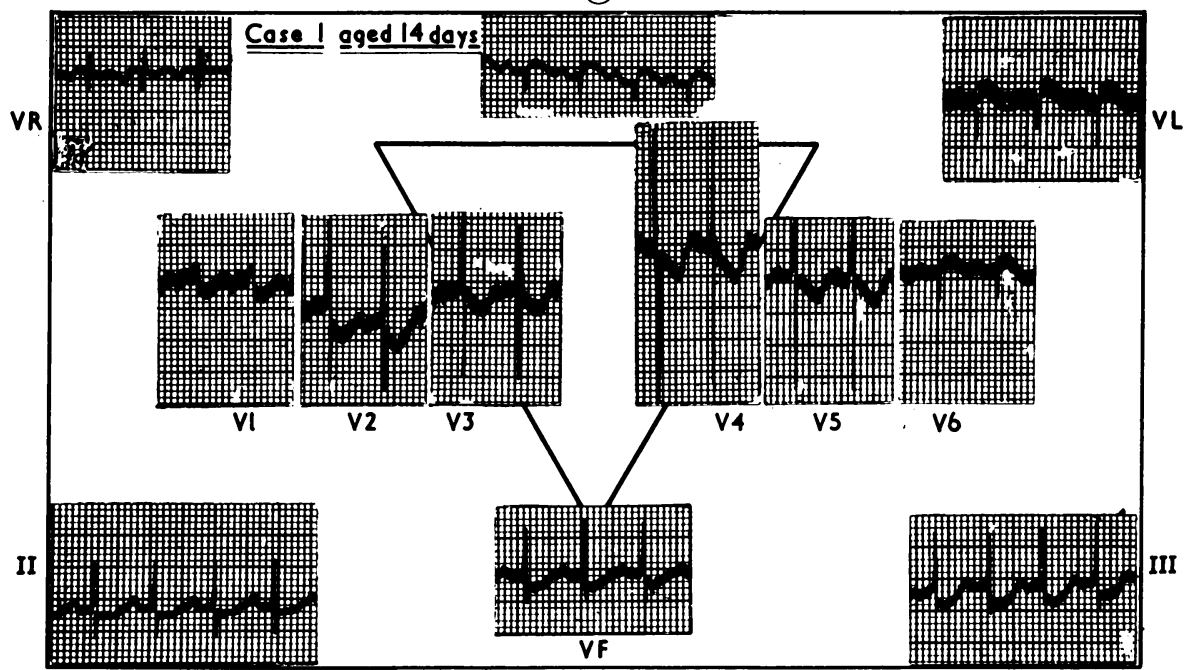

Rote

(b)

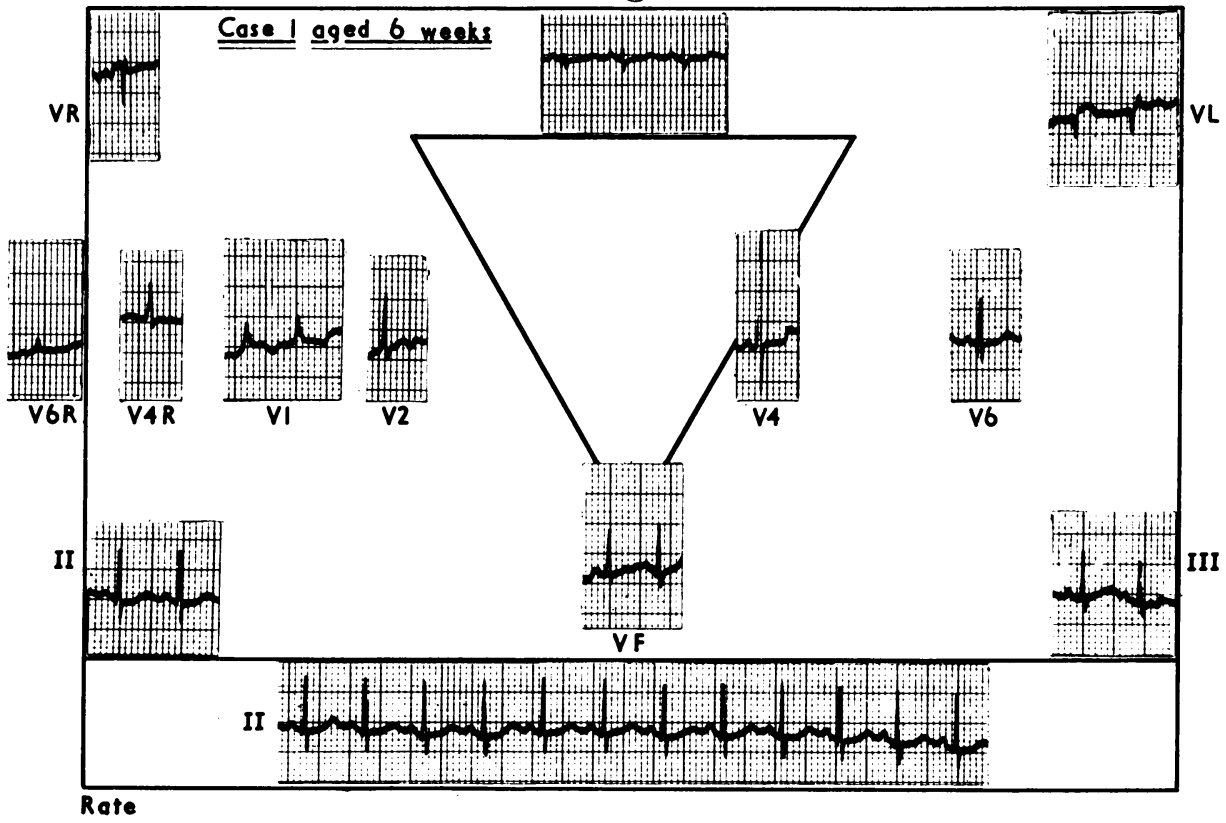

Fig. 1.-Case 1 (a) 14 days, ECG showing changes of anterolateral infarction. (b) at 6 weeks, ECG showing resolving changes of anterolateral infarction.

$14 \mathrm{mmHg}$. There was no evidence of a left-to-right shunt but the atrial oxygen saturation of the pulmonary venous sample was $91 \%$, consistent with pulmonary oedema. The left ventricle was not entered. An injection of $76 \%$ Urograffin into the pulmonary artery showed on recirculation an enlarged left ventricle which contracted well. There was no evidence of a left-to-right shunt. The cineaortogram showed a localized coarctation of the aorta. A duct was not shown and the coronary arteries appeared to arise normally (Fig. 2). Very good collaterals were also shown. The infant was operated on the same day by 


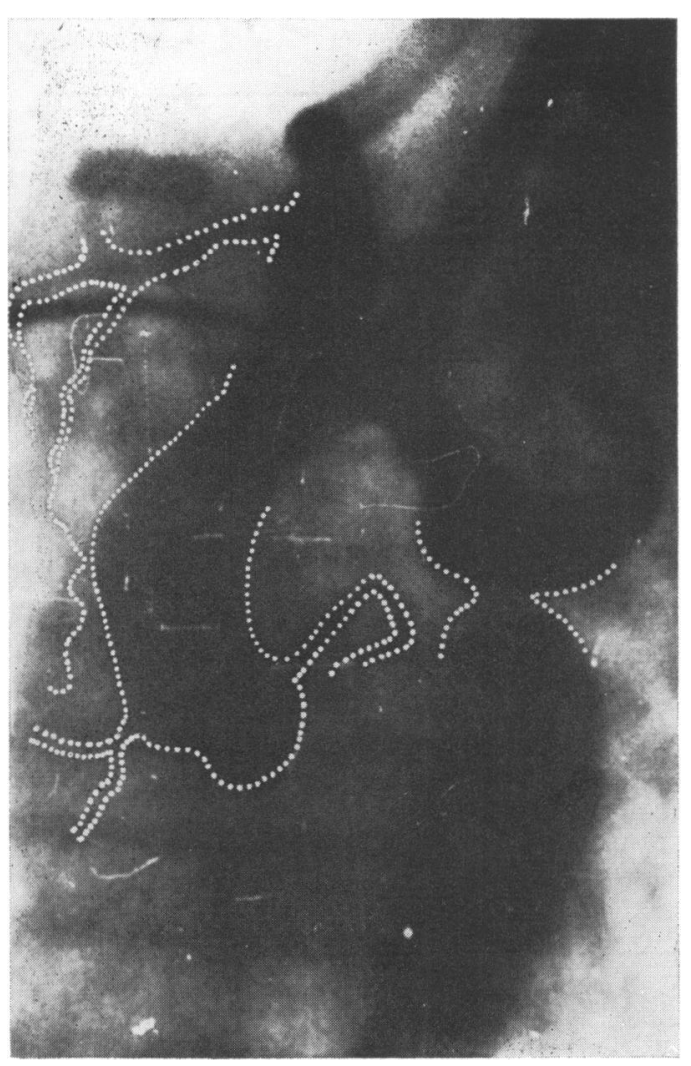

Fig. 2.-Case 1 at 17 day's, cineaortogram showing localized coarctation of the aorta and no evidence of a persistent ductus arteriosus. The coronary arteries arise normally.
Mr. W. P. Cleland, who found a localized postductal coarctation of the aorta, which he resected. The ductus arteriosus was just probe patent, and was ligated; the aortic arch was of good calibre.

The postoperative course was uneventful, and by 6 weeks the ECG evidence of anterolateral infarction was resolving (Fig. 1b). The infant was alive and well $1 \frac{1}{2}$ years after operation, with normal femoral and foot pulses. Both chest $x$-ray and ECG are now normal. The ST changes on the ECG had resolved completely within 3 months of the operation.

Case 2. The other patient was the second child of healthy British parents, born at 37 weeks' gestation, birthweight $3 \cdot 12 \mathrm{~kg}$. He was always a slow feeder and increasing shortness of breath rapidly became apparent. He was found to be in heart failure at 1 week of age without palpable femoral pulses. He was treated with digitalis and diuretics and was transferred at 11 days of age with a diagnosis of coarctation of the aorta.

On admission he was markedly tachypnoeic but there was no hepatosplenomegaly and the jugular venous pressure was not raised. The brachial pulses were brisk and the blood pressure was $125 / 90 \mathrm{mmHg}$ in both arms and $40 / 20 \mathrm{mmHg}$ in both legs (by oscillometer). The cardiac impulse was right ventricular in character. The second heart sound was normally split, and apical third and fourth heart sounds were clearly audible; a soft ejection systolic murmur was heard at the left sternal edge. The ECG (Fig. 3a) showed an indeterminate axis and right ventricular hypertrophy; there were ST changes suggestive of an anterolateral infarct with qs pattern in leads $I$ and aVL. Chest $x$-ray showed moderate cardiomegaly and clear lung fields. A clinical diagnosis of coarctation of the aorta was made and anomalous origin of the left coronary artery from the pulmonary artery queried on the basis of the ECG changes.

Medical treatment was continued but the following

TABLE

Haemodynamic Data

\begin{tabular}{|c|c|c|c|c|c|c|}
\hline \multirow{3}{*}{ Site } & \multicolumn{4}{|c|}{ Pressure (mmHg) } & \multirow{2}{*}{\multicolumn{2}{|c|}{$\mathrm{O}_{2}$ Saturation }} \\
\hline & \multicolumn{2}{|c|}{ Dynamic } & \multicolumn{2}{|c|}{ Mean } & & \\
\hline & Case 1 & Case 2 & Case 1 & Case 2 & Case 1 & Case 2 \\
\hline $\begin{array}{l}\text { Superior vena cava } \\
\text { Inferior vena cava } \\
\text { Right atrium } \\
\text { Right ventricle } \\
\text { Pulmonary artery } \\
\text { Pulmonary vein } \\
\text { Left atrium } \\
\text { Left ventricle } \\
\text { Ascending aorta } \\
\text { Femoral artery }\end{array}$ & $\begin{array}{r}75 / 14 \\
75 / 40 \\
\\
130 / 100\end{array}$ & $\begin{array}{l}39 / 5 \\
39 / 18 \\
156 / 18 \\
110 / 95\end{array}$ & $\begin{array}{r}10 \\
50 \\
25 \\
120\end{array}$ & $\begin{array}{r}3 \\
26 \\
14\end{array}$ & $\begin{array}{l}55 \\
47 \\
51 \\
51 \\
53 \\
92 \\
91 \\
93\end{array}$ & $\begin{array}{l}82 \\
86 \\
85 \\
86 \\
83 \\
97 \\
97 \\
\end{array}$ \\
\hline
\end{tabular}

Case 1 breathing room air. Case 2 breathing 100\% oxygen. 
(a)

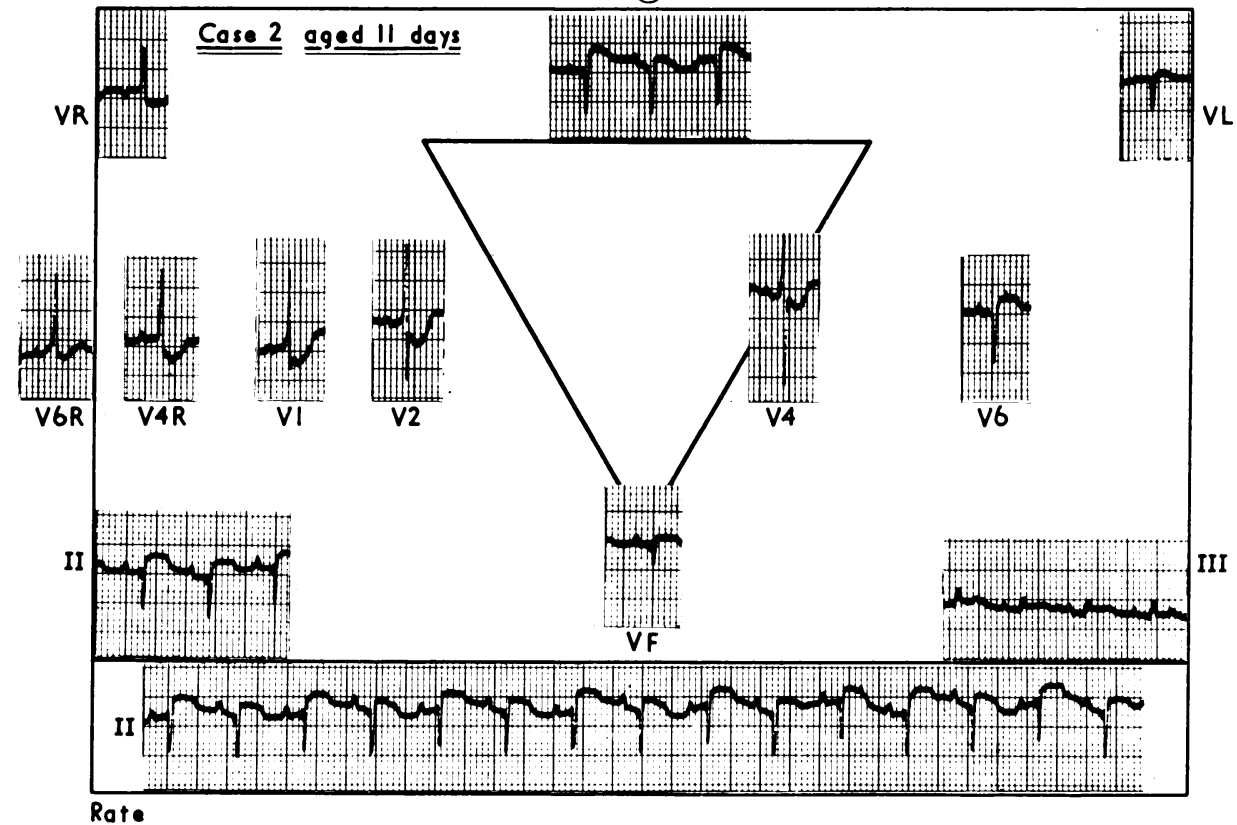

(b)

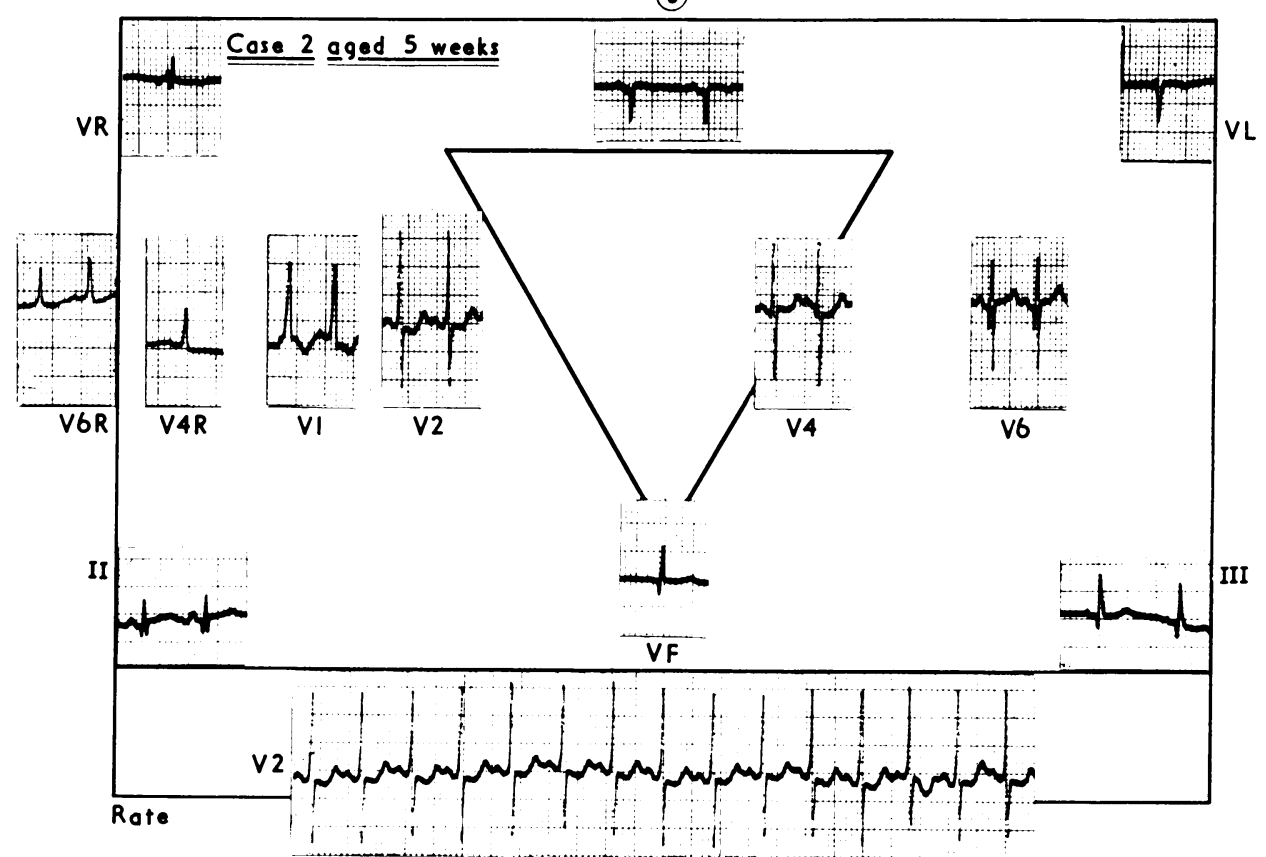

FIG. 3.-Case 2 (a) 11 days, ECG showing changes of anterolateral infarction; (b) at 5 weeks, ECG showing resolving changes of anterolateral infarction. 
day the baby screamed and collapsed, becoming cyanosed and cold with bilateral râles in the lungs. He was thought to have had an episode of angina and of acute left ventricular failure, and after resuscitation with oxygen, morphia, and i.v. frusemide he was taken to the catheter laboratory where a right heart catheterization was carried out from the femoral vein with him breathing $100 \%$ oxygen throughout. The left heart was entered through a patent foramen ovale. The findings (Table) were of normal right-sided pressures for his age but of a resting left atrial pressure raised to $14 \mathrm{mmHg}$ and a left ventricular end-diastolic pressure of $18 \mathrm{mmHg}$. The left ventricular systolic pressure was $156 \mathrm{mmHg}$ and the gradient across the coarctation was $46 \mathrm{~mm}$, the femoral artery pressure being 110/95 (mean $100 \mathrm{mmHg}$ ). There was no evidence of any intracardiac shunt. The left ventricular angiogram showed a slightly enlarged left ventricle which contracted well. No ventricular septal defect was seen. A localized coarctation of the aorta was shown but there was no evidence of persistence of the ductus arteriosus. The collateral vessels were less well developed than in the previous patient. The coronary arteries arose normally. Immediately after the procedure Professor $H$. H. Bentall resected a localized postductal coarctation and ligated a ligamentum arteriosus; the aortic arch was of good calibre.

The postoperative course was uneventful. A year later the baby was alive and well though the femoral pulses were slightly delayed, suggesting mild residual or recoarctation. Both chest $x$-ray and ECG were normal. The ST segment changes on the ECG were resolving by 5 weeks (Fig. 3b) and resolved by 3 months.

\section{Discussion}

The two babies described had isolated postductal coarctation of the aorta, and will be considered jointly. Both were in heart failure by the end of the first week of life; one (Case 2) in left ventricular failure, and the other (Case 1) in biventricular failure.

It seems clear that postductal coarctation of the aorta is a significant lesion in utero (Calodney and Carson, 1950; Rudolph, 1966), and hence conducive to the development of collateral arteries (Bahn et al., 1951; Lang and Nadas, 1956). Failure to develop good collaterals may be of major importance in the development of cardiac failure in infants with postductal coarctation (Olney and Stephens, 1950; Calodney and Carson, 1950; Bahn et al., 1951). However, in the two infants described, collaterals were well shown angiocardiographically, and thus this factor did not seem to be the determining cause of their heart failure. The importance of a concurrent respiratory or other febrile illness which might precipitate heart failure has been stressed (Calodney and Carson, 1950), but was not a feature in the clinical course of our two infants. Attention has been drawn to the contribution of a hypoplastic aortic arch as a determinant of heart failure in infants with associated localized constriction (Olney and Stephens, 1950; Sinha et al., 1969), but the aortic arch of both our patients appeared of good calibre both angiographically and on direct inspection at the time of operation.

Both infants had severe coarctation: in one of them (Case 2) there was systolic hypertension of $156 \mathrm{mmHg}$ in the upper segment, which constitutes severe hypertension for a newborn infant. This indicates that the left ventricle was powerful and had probably been able to hypertrophy considerably before failing. Since the left ventricle normally weighs less than the right at birth (Emery and MacDonald, 1960) and increases its mass throughout the first few months of life (Recavarren and AriasStella, 1964), it is clear that the increasing hypertrophy required of the left ventricle in severe coarctation of the aorta would make additional demands on the available myocardial blood supply. It has been shown that coronary artery flow is increased in coarctation of the aorta (Gupta and Wiggers, 1951; Vlodaver and Neufeld, 1968). These latter authors have also shown that the increased coronary flow may in turn be responsible for intimal proliferation and degeneration which they were able to show in the coronary arteries of children with coarctation of the aorta. Coronary endarteritis has been described in an infant with isolated postductal coarctation of the aorta (Oppenheimer and Esterly, 1966). Myocardial necrosis has been shown in young infants dying from congenital cardiac defects (Esterly and Oppenheimer, 1967), and more specifically in infants dying from coarctation of the aorta (Tawes et al., 1969a, b), but the latter authors were unable to relate their findings to the ECG changes. The ECG findings in our two patients were suggestive of anterolateral infarction and the changes regressed after resection of the coarctation. The episodes of screaming and collapse in one of them (Case 2) might possibly have related to an episode of acute myocardial ischaemia. One might assume that despite the increased coronary blood flow induced by the upper segment hypertension nevertheless it was insufficient to meet the demands of the hypertrophying left ventricle so that myocardial ischaemia and possibly necrosis resulted. Similar ECG changes are well known in anomalous left coronary artery originating from the pulmonary artery (Burch and DePasquale, 1962) but the aortogram excluded this anomaly in these infants and the ECG changes regressed completely.

The ECG pattern of infarction has been described in infants with endocardial fibroelastosis (Lambert 
and Vlad, 1958), and the association of endocardial fibroelastosis with coarctation of the aorta is well known (Forfar et al., 1964; Moller et al., 1964). However, endocardial fibroelastosis is usually held to be secondary to left ventricular failure, and the early symptomatology, relatively good left ventricular function, and rapid improvement after resection of the coarctation, all mitigate against endocardial fibroelastosis being a primary or significant problem in the two infants described.

It is concluded, therefore, that myocardial ischaemia and left ventricular necrosis secondary to severe coarctation of the aorta may be a major factor in the production of heart failure in the newborn infant with isolated postductal coarctation of the aorta.

I thank Drs. M. Wilmers (South London Hospital) and D. Stone (Royal Berkshire Hospital), who kindly referred the patients, and also Professor J. F. Goodwin for his helpful criticism.

\section{REFERENCES}

Bahn, R. C., Edwards, J. E., and DuShane, J. W. (1951). Coarctation of the aorta as a cause of death in early infancy. Pediatrics, $8,192$.

Burch, G. E., and DePasquale, N. P. (1962). The electrocardiogram in certain anomalies of the coronary arteries. American Heart fournal, 64, 38.

Calodney, M. M., and Carson, M. J. (1950). Coarctation of the aorta in early infancy. Fournal of Pediatrics, 37, 46.

Emery, J. L., and MacDonald, M. S. (1960). The weight of the ventricles in the later weeks of intra-uterine life. British Heart Fournal, 22, 563.

Esterly, J. R., and Oppenheimer, E. H. (1967). Some aspects of cardiac pathology in infancy and childhood. IV. Myocardial and coronary lesions in cardiac malformations. Pediatrics, 39, 896.

Forfar, J. O., Miller, R. A., Bain, A. D., and Macleod, W. (1964). Endocardial fibroelastosis. British Medical fournal, 2, 7.

Gasul, B. M., Arcilla, R. A., and Lev, M. (1966). Heart Disease in Children: Diagnosis and Treatment, p. 906. Lippincott, Philadelphia; Pitman, London.

Glass, I. H., Mustard, W. T., and Keith, J. D. (1960). Coarctation of the aorta in infants: a review of 12 years' experience. Pediatrics, 26, 109.

Gupta, T. C., and Wiggers, C. J. (1951). Basic hemodynamic changes produced by aortic coarctation of different degrees. Circulation, 3, 17.

Keith, J. D., Rowe, R. D., and Vlad, P. (1967). Heart Disease in Infancy and Childhood, 2nd ed., p. 4. Macmillan, New York

Kirklin, J. W., Burchell, H. B., Pugh, D. G., Burke, E. C., and Mills, S. D. (1952). Surgical treatment of coarctation of the aorta in a ten week old infant: report of a case. Circulation, 6,410 .

Lambert, E. C., and Vlad, P. (1958). Primary endomyocardial disease. Pediatric Clinics of North America, 5, 1057.

Lang, H. T., Jr., and Nadas, A. S. (1956). Coarctation of the aorta with congestive heart failure in infancy. Medical treatment. Pediatrics, 17, 5.

Moller, J. H., Lucas, R. V., Jr., Adams, P., Jr., Anderson, R. C., Jorgens, J., and Edwards, J. E. (1964). Endocardial fibroelastosis; a clinical and anatomic study of 47 patients with emphasis on its relationship to mitral insufficiency. Circulation, 30, 759.

Olney, M. B., and Stephens, H. B. (1950). Coarctation of the aorta in children. Fournal of Pediatrics, 37, 639.

Oppenheimer, E. H., and Esterly, J. R. (1966). Some aspects of cardiac pathology in infancy and childhood. II. Unusual coronary endarteritis and congenital cardiac malformations. Bulletin of the Fohns Hopkins Hospital, 119, 343.

Recavarren, S., and Arias-Stella, J. (1964). Growth and development of the ventricular myocardium from birth to adult life. British Heart Fournal, 26, 187.

Rowe, R. D., and Mehrizi, A. (1968). The Neonate with Congenital Heart Disease, p. 76. Saunders, Philadelphia.

Rudolph, A. M. (1966). Prenatal and perinatal influences of congenital heart disease. In The Heart and Circulation in the Newborn Infant, p. 142. Grune and Stratton, New York.

Sinha, S. N., Kardatzke, M. L., Cole, R. B., Muster, A. J., Wessel, H. U., and Paul, M. H. (1969). Coarctation of the aorta in infancy. Circulation, 40, 385.

Tawes, R. L., Jr., Aberdeen, E., Waterston, D. J., and Carter, R. E. B. (1969a). Coarctation of the aorta in infants and children. Circulation, 39-40, Suppl. 1, 173.

Tawes, R. L., Jr., Berry, C. L., Aberdeen, E., and Graham, G. R. (1969b). Myocardial ischemia in infants: its role in three common congenital cardiac anomalies. Annals of Thoracic Surgery, 8, 383.

Vlodaver, Z., and Neufeld, H. N. (1968). The coronary arteries in coarctation of the aorta. Circulation, 37, 449.

Correspondence to Dr. K. A. Hallidie-Smith, Royal Postgraduate Medical School, Hammersmith Hospital, Du Cane Road, London W12 0HS. 